Article

\title{
Spatial-Temporal Dynamic Analysis of Land Use and Landscape Pattern in Guangzhou, China: Exploring the Driving Forces from an Urban Sustainability Perspective
}

\author{
Siqi Liu ${ }^{1,2,3, *}$, Qing Yu ${ }^{2,4}$ and Chen Wei ${ }^{1}$ \\ 1 Shaanxi Provincial Land Engineering Construction Group Co., Ltd., Xi'an 710075, China; \\ 2015226043@chd.edu.cn \\ 2 The Center for Housing Innovations of the Chinese University of Hong Kong, Hong Kong 999077, China; \\ kjc@aku.edu.cn \\ 3 Institute of Land Engineering and Technology, Shaanxi Provincial Land Engineering Construction Group \\ Co., Ltd., Xi'an 710024, China \\ 4 Natural Resources Monitoring Center of Zhejiang Province, Zhejiang 310000, China \\ * Correspondence: 4102090209@chd.edu.cn
}

Received: 23 October 2019; Accepted: 22 November 2019; Published: 26 November 2019

\begin{abstract}
Rapid urbanization is one of the most important factors causing land-use change, which mainly results from the orientation of government policies, adjustment of industrial structure, and migration of the rural population. Land use and land cover change (LUCC) is the natural foundation of urban development that is significantly influenced by human activities. By analyzing the LUCC and its inner driving force, as well as landscape pattern change, human activity and urban sustainable development can be better understood. This research adopted a geographic information system (GIS) and remote sensing (RS) technology to comprehensively analyze land use of Guangzhou, respectively, in 1995, 2005, and 2015. Fragmentation Statistics (FRAGSTATS) is the most authoritative software to calculate landscape metrics. Landscape pattern change was analyzed by FRAGSTATS. The results showed that urban land significantly increased from $16.33 \%$ in 1995 to $36.05 \%$ in 2015 . Farmland greatly decreased from $45.16 \%$ in 1995 to $27.82 \%$ in 2005 and then slightly decreased to $25.10 \%$ in 2015. In the first decade, the non-agricultural conversion of rural land and the expansion of urban land was the dominant factor that led to the change. In the second decade, urban land had been supplemented through the redevelopment of low-efficiency land. The fragmentation of landscape patterns significantly increased from 1995 to 2005 and slightly decreased from 2005 to 2015. It indicated that the change in land use in the second decade was different from that in the first. This difference mainly resulted from three aspects: (1) urban development area and ecological conservation area were clearly defined in Guangzhou; (2) many small towns had developed into urban centers, and the scattered urban land gathered into these centers; (3) the establishment of greenway improved the connection of fragmented patches. After that, this study discussed land-use change and its causes and proposed the trend of urban development from the perspective of sustainability.
\end{abstract}

Keywords: LUCC; landscape pattern; fragmentation; non-agricultural conversion of rural land; urban green space

\section{Introduction}

In the past few decades, many parts of the world have experienced rapid urbanization. However, urbanization in China is considered to be the fastest and the most extensive one [1]. The area of land-use 
change in China from 1980 to 2015 accounted for $17 \%$ of the total land area of China. In particular, the net increment of construction land area is the largest worldwide. Rapid urbanization is the major cause of land-use change [2]. China's urbanization is divided into two stages. The urbanization process from 1949 to 1978 was slow and tortuous; after which, China's urbanization entered a period of rapid development with the urbanization rate increased from $17.9 \%$ in 1978 to $59.58 \%$ in 2018. Especially after 1995, China's urbanization increment was as much as 1.5\% per year [3]. The focus of urbanization had gradually changed from the expansion of metropolitan areas to the overall construction of small cities and towns in the central and western regions.

Fast economic growth supports rapid urbanization. Conversely, rapid urbanization provides the material basis for economic development, such as land resources and labor force. However, this economy-oriented mode neglected the development of society and the environment. In this context, urban sustainability is proposed to mitigate the negative impact of rapid urbanization on society and the environment. Over time, urban sustainability has been developed by a variety of approaches, including efficient land use that focuses on compact, the transformation of industrial structure, and a healthy ecological environment that focuses on human living quality improvements [4]. Particularly, environmental issues have received widespread attention with environmental problems, including land degradation, contamination, and the decline in green space, becoming evident [5]. On the level of urban construction, increasing urban green space is considered to be an effective way to alleviate these problems and to improve living quality. Urban green space, called "the lung of the city", is an essential part of the urban ecosystem. It can offer multiple ecosystem services, including climate dampening, water supply, and nutrient cycle [6]. Urban green space plays an active role in maintaining ecosystem stability and forming the urban landscape, meeting urban ecological service functions, and improving urban environmental quality. What's more, it is also an important way to achieve urban sustainable development $[7,8]$.

The fundamental components of urban green space are landscape patches with various sizes and shapes [9]. Every patch has a regular structure, specific function, and relative independence. The spatial distribution of landscape patches is called landscape pattern, which is generated under the influence of many factors [10]. Landscape pattern is not only the arrangement and combination of landscape elements with different sizes and shapes in space but also the spatial manifestation of landscape heterogeneity [11]. It can embody urban development characteristics, including land resources, urban morphology, and urban management [12].

Land use and land cover change (LUCC) is the natural foundation that significantly influences human existence development. It is a dynamic process that can lead to changes in landscape patterns $[13,14]$. Urban development policies directly affect human activities, which directly affects the change in land use. Conversely, by studying the optimization of land use, we can better formulate urban development policies. With the continuous improvement of geographic information system (GIS) technology and the establishment of a remote sensing (RS) platform, China has entered a period of remote sensing and big data. RS technology is widely used in LUCC monitoring, which has the characteristics of large area coverage, high precision, and timeliness $[15,16]$. RS data has become the most important and stable data source for LUCC analysis [17].

Many researchers [18-20] attempted to analyze LUCC and landscape pattern change, respectively, in China, but they seldom integrate both of them to discuss the implication for urban sustainability. From the perspective of urban planning and sustainability, this research analyzed the internal driving force of the change by using GIS and RS technologies. It aimed at (1) analyzing spatial-temporal dynamics of LUCC and landscape pattern from 1995 to 2015; (2) figuring out the internal driving force of LUCC and landscape pattern from 1995 to 2015; (3) assessing the completion and the value of green space system construction; (4) forecasting the trend of land use and putting forward proposals about improving environmental quality. 


\section{Study Area}

Guangzhou is the capital and largest city of Guangdong province in the south of China (from $112^{\circ} 57^{\prime}$ to $114^{\circ} 03^{\prime}$ E longitude, $22^{\circ} 26^{\prime}$ to $23^{\circ} 56^{\prime} \mathrm{N}$ latitude), which is located on the Pearl River Delta, adjacent to Hong Kong and the Macao Special Administrative Region. Moreover, Guangzhou is one of the fastest-growing cities in China in terms of urbanization. It has been playing a crucial role in China's economic reform and development since 1978. The urban population grew from $6,122,000$ in 1992 to 14,043,000 in 2016. In recent years, it has continued to push forward the adjustment of urban spatial layout, realizing the transformation from single-center to multi-center development of urban spatial structure, expanding the city to its suburbs, and making great changes in land use.

In this research, we selected eight districts of Guangzhou, including Yuexiu district, Liwan district, Haizhu district, Tianhe district, Baiyun district, Huangpu district, Panyu district, Huadu district, as study areas (Figure 1). They form the core areas of Guangzhou, which have a relatively higher urbanization proportion and faster urbanization speed. Nansha district, Zengcheng district, and Conghua district belong to the Guangzhou eco-tourism area and ecological agriculture area, whose land cover types are mainly forestland and farmland. They are less affected by rapid urbanization. Therefore, these areas were not in the scope of this research.

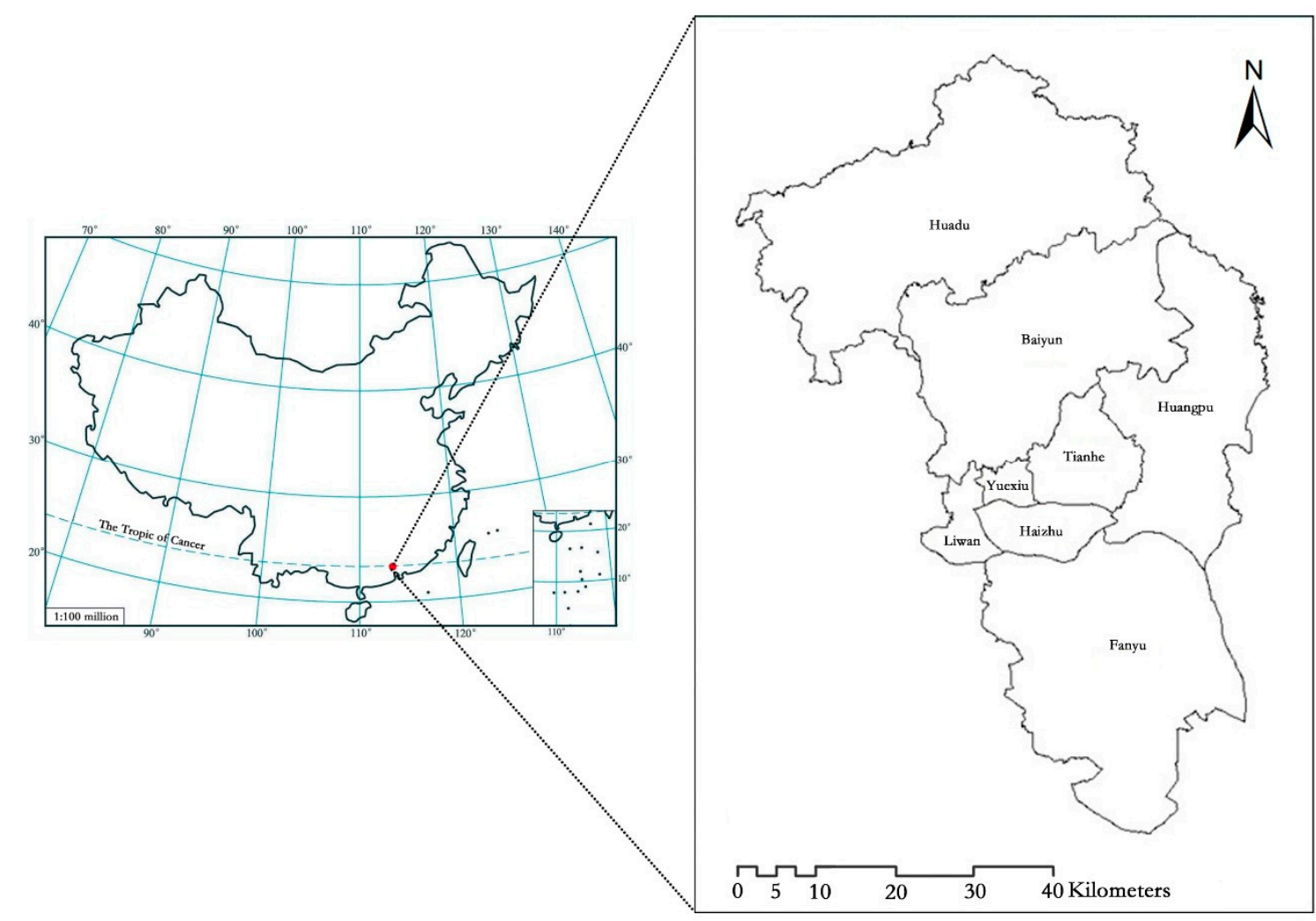

Figure 1. Study areas (Yuexiu district, Liwan district, Haizhu district, Tianhe district, Baiyun district, Huangpu district, Panyu district, Huadu district).

\section{Materials and Methods}

\subsection{Data Source}

The research data was used to dynamically analyze LUCC and landscape pattern from 1995 to 2015. Three years' satellite image data $(1995,2005$, and 2015) was selected, coming from Landsat5 and Landsat8. We used the Landsat5 image as the data source of 1995 and 2005, while Landsat8 image as 2015 image data, as it just launched in 2013. Both the spatial resolution of Landsat5 and Landsat 8 are $30 \times 30 \mathrm{~m}$. As a new satellite, the Landsat 8 had been greatly improved in the aspects of 
image resolution, number of wave band, and scanning mode compared with other previous satellites. In addition, the time of images acquired in different years should be relatively close, and in order to minimize the weather's negative influence on analysis, the images were selected with low cloud cover. As a result, the acquisition time of the image was 19 January 2015, 23 November 2005, 30 December 1995, respectively.

\subsection{Analysis Method for LUCC}

The Environment for Visualizing Image (ENVI) is complete remote sensing (RS) image processing platform, which is developed by Interactive Data Language (IDL). It is powerful in remote sensing (RS) image display, processing, and analysis, including image enhancement, correction, classification, and analysis of multiple features [21]. It is an effective approach to research LUCC.

Image data were processed by ENVI, and land cover involved six classes in this study: water, forestland, grassland, urban land, farmland, and bare land (including unused land). Thus, we obtained the green land information from classification results, including farmland, forestland, and grassland, as well as the changes in urban land and bare land, which enabled us to analyze the changes in the landscape pattern afterward.

The classification of land cover leveraged a collection of various technologies and approaches. The green land information extraction should choose suitable bands. In this study, six original bands were used except band 6 (thermal infrared band). Band 1, band 2, and band 3 are visible light ones, and band 1 has the greatest penetration of water. Band 4 is the near-infrared band, which reflects the high-reflection area of plants and reflects a large amount of plant information. Besides, band 5 is the short-wave infrared band (SWIR), which is sensitive to plant and soil moisture content. Band 7, the middle infrared band, has the longest wavelength in those six bands [22]. Due to the characteristics of each band of Landsat 4-5 thematic mapper (TM) image, there is redundant information between each band. In order to reduce the interference between the bands, we should select several bands with a large amount of information and less correlation to integrate and analyze afterward. We first analyzed the correlation of six original bands, as Table 1 shows below.

Table 1. Landsat 4-5 thematic mapper (TM) original bands correlation matrix in 2015.

\begin{tabular}{ccccccc}
\hline Correlation & Band 1 & Band 2 & Band 3 & Band 4 & Band 5 & Band 7 \\
\hline Band 1 & 1 & & & & & \\
Band 2 & 0.970924 & 1 & & & & \\
Band 3 & 0.956297 & 0.983961 & 1 & & & \\
Band 4 & 0.62476 & 0.709536 & 0.662028 & 1 & & \\
Band 5 & 0.818552 & 0.870241 & 0.861311 & 0.904781 & 1 & \\
Band 7 & 0.907242 & 0.923027 & 0.925918 & 0.779751 & 0.960959 & 1 \\
\hline
\end{tabular}

Band 1 contains much more information than band 2 and band 3, but a reflection of surface features except water is generally lower than band 4 . In addition, band 1 is greatly disturbed by the atmosphere [23]. According to the correlation between bands and the amount of information contained, TM bands 2, 3, 4 were selected for combination. When extracting information, we used six original bands' data. Moreover, it may also include various kinds of "derivative" band data, like the principal components, NDVI (normalized difference vegetation index), and other ratio indices [24]. The principal component transform, also known as K-L transform, is a multidimensional orthogonal linear transformation based on the statistical characteristics. It can be compressed correlated multi-band to fewer fully independent bands data, to make image interpretation easier [25]. Normalized difference vegetation index (NDVI) is a simple graphical indicator, which is calculated from the visible (VIS) and near-infrared (NIR) light reflected by vegetation $[26,27]$. The formula is:

$$
\mathrm{NDVI}=(\mathrm{NIR}-\mathrm{VIS}) /(\mathrm{NIR}+\mathrm{VIS})
$$


Figure 2a-c below are the results of principal component transformation by using principal components tool in ENVI, together with NDVI results (Figure 2d), which we could compare directly.

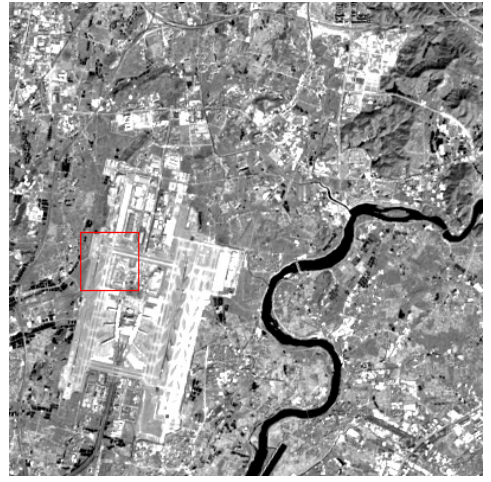

(a)

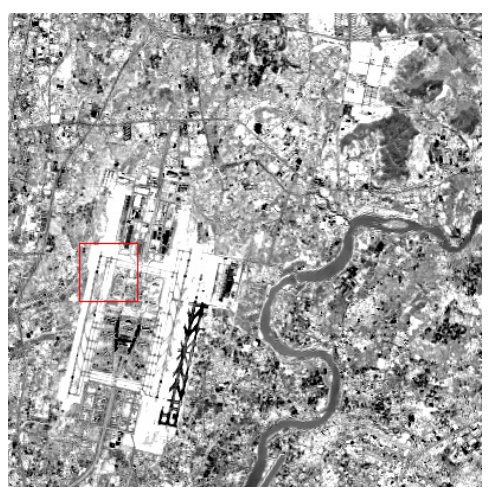

(c)

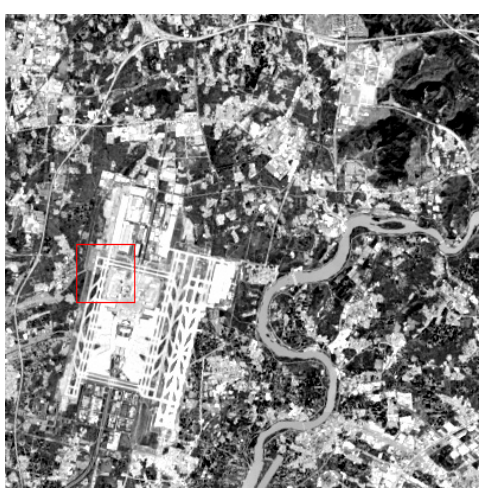

(b)

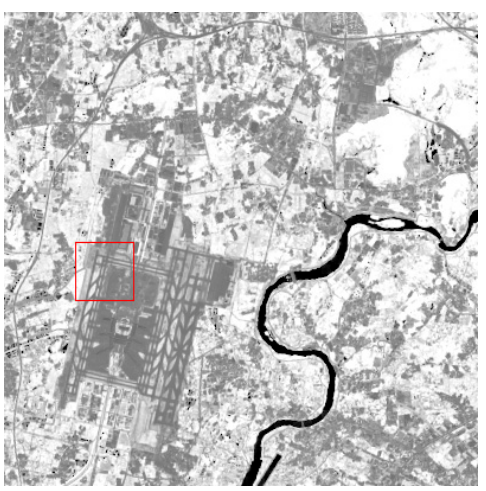

(d)

Figure 2. The (a) shows PC1; the (b) shows PC2; the (c) shows PC3; the (d) shows NDVI results. PC, principal component; NDVI, normalized difference vegetation index.

The first principal component (PC1) contains the maximum variance percentage, the second principal component (PC2) contains the second large variance, and so on. The last band's principal component, due to the less variance, most of which is caused by the original spectrum noise, it appears as noise [28-30]. From the four figures above, it is obvious that they showed different characteristics of different objects. For example, water was very clear in PC1 and NDVI results.

According to the correlation coefficient of each band, the optimal band combination was selected. In this study, we selected the first principal component band (PC1) and NDVI, as well as TM bands 2, 3, 4 for correlation analysis of each band. After the analysis and comparison of the correlation of images, we found the combination of band 3, PCI, and NDVI had a better visual interpretation result for classification reference, as shown in Table 2.

Table 2. TM bands 2, 3, 4, PC1, and NDVI correlation matrix in 2015.

\begin{tabular}{cccccc}
\hline Correlation & PC1 & NDVI & Band 2 & Band 3 & Band 4 \\
\hline PC1 & 1 & & & & \\
NDVI & 0.338435 & 1 & & & \\
Band 2 & 0.912088 & 0.101084 & 1 & & \\
Band 3 & 0.888872 & 0.062101 & 0.983961 & 1 & \\
Band 4 & 0.924823 & 0.507719 & 0.709536 & 0.662028 & 1 \\
\hline
\end{tabular}

${ }_{1}^{1} \mathrm{PC} 1$ = the first principal component band; NDVI = normalized difference vegetation index 
In this study, we started with a preliminary interpretation in the research area by using the supervised classification, and then used a combination of supervised classification result (maximum likelihood classification) and decision tree classification. In supervised classification, a region of interest (ROI) was selected as samples, which was acquired on the basis of prior knowledge experience and higher resolution images. According to the rules of knowledge and successive comparison, decision tree classification extracted various types of surface objects from the image. [31,32].

TM image has some limitations, such as the same type of objects have different spectrums, and different types of objects may have a similar spectrum. Therefore, as a consequence, there might be certain omission errors. The step of visual interpretation, combined with a large number of field research, for correcting is necessary, which could minimize the errors. Thus, the image classification result could reflect the objects' information on the ground as far as possible. After classification, accuracy evaluation is indispensable. In this study, we firstly selected some parts of classification results and compared them with the Google Earth image (Figures 3 and 4), following the inspection standards.

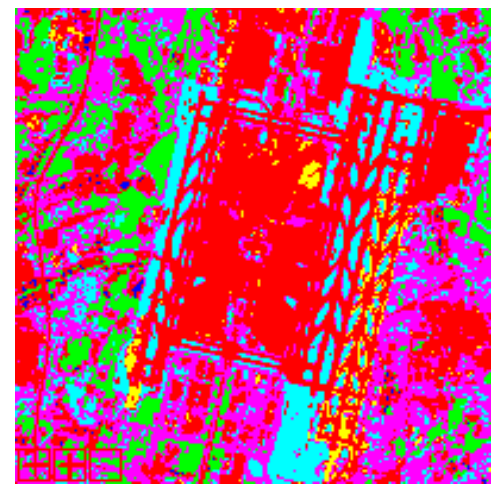

(a)

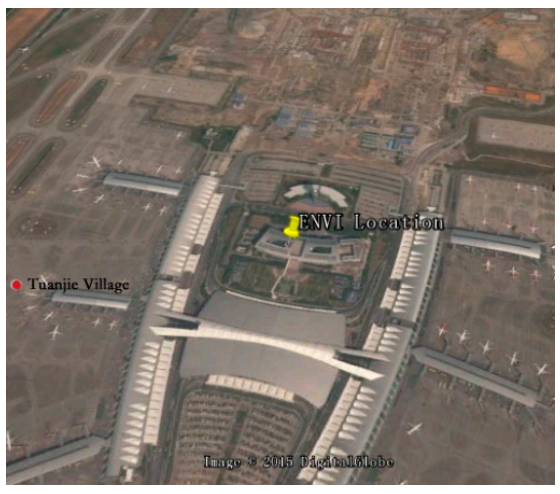

(b)

Figure 3. Classification results, where the red area represents urban land (a); the real image of the airport by Google Earth with the same location (b).

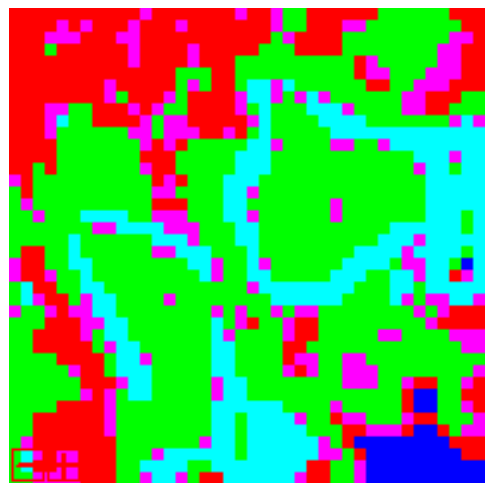

(a)

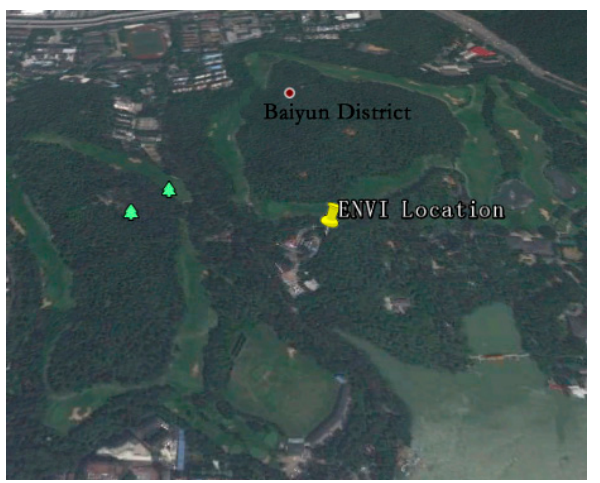

(b)

Figure 4. Classification results, where the cyan area represents grassland, and the green area is forestland (a); the real image of the park by Google Earth with the same location (b).

Then, the image classification accuracy was also evaluated using the Kappa coefficient index [33]. It is an important and also widely used index to measure the accuracy of image classification. The classification results were assessed by using a randomly scattered diagram and generating the confusion matrix in ENVI [34] (Tables 3-5).

According to the accuracy assessment, the overall accuracy and kappa coefficient were both above 0.9 ; as a result, the classification results were approximately acceptable. 
Table 3. Confusion matrix of the classification results in 2015.

\begin{tabular}{|c|c|c|c|c|c|c|c|}
\hline & Water & Urban Land & Forestland & Farmland & Grassland & Bare Land & Total \\
\hline Water & 148 & 1 & 0 & 0 & 0 & 1 & 150 \\
\hline $\begin{array}{l}\text { Urban } \\
\text { land }\end{array}$ & 6 & 149 & 1 & 0 & 0 & 0 & 156 \\
\hline Forestland & 2 & 0 & 149 & 0 & 0 & 0 & 152 \\
\hline Farmland & 0 & 7 & 8 & 136 & 0 & 0 & 151 \\
\hline Grassland & 0 & 3 & 2 & 1 & 46 & 1 & 53 \\
\hline Bare land & 0 & 3 & 0 & 0 & 0 & 55 & 58 \\
\hline Total & 156 & 163 & 160 & 137 & 47 & 57 & 720 \\
\hline
\end{tabular}

Overall Accuracy $=(683 / 720) 94.8611 \%$. Kappa Coefficient $=0.9364$.

Table 4. Confusion matrix of the classification results in 2005.

\begin{tabular}{cccccccc}
\hline & Water & Urban Land & Forestland & Farmland & Grassland & Bare Land & Total \\
\hline Water & 149 & 1 & 0 & 1 & 0 & 1 & 152 \\
Urban & 5 & 144 & 1 & 0 & 0 & 0 & 150 \\
land & 2 & 0 & 148 & 1 & 0 & 0 & 151 \\
Forestland & 2 & 4 & 1 & 142 & 0 & 0 & 150 \\
Farmland & 3 & 1 & 2 & 3 & 51 & 0 & 57 \\
Grassland & 0 & 1 & 0 & 0 & 0 & 59 & 60 \\
Bare land & 0 & 151 & 152 & 147 & 51 & 60 & 720 \\
Total & 159 & &
\end{tabular}

Overall Accuracy $=(693 / 720) 96.2500 \%$. Kappa Coefficient $=0.9537$.

Table 5. Confusion matrix of the classification results in 1995.

\begin{tabular}{cccccccc}
\hline & Water & Urban Land & Forestland & Farmland & Grassland & Bare Land & Total \\
\hline Water & 147 & 0 & 2 & 0 & 0 & 0 & 149 \\
Urban & 9 & 146 & 0 & 0 & 0 & 0 & 155 \\
land & 0 & 2 & 148 & 1 & 0 & 0 & 151 \\
Forestland & 1 & 3 & 141 & 0 & 0 & 151 \\
Farmland & 1 & 0 & 0 & 0 & 0 & 56 & 58 \\
Grassland & 0 & 2 & 157 & 144 & 50 & 56 & 720 \\
Bare land & 0 & 156 & Overall Accuracy $=(688 / 720) 95.5556 \%$. Kappa Coefficient $=0.9451$. &
\end{tabular}

\subsection{Landscape Pattern Analysis}

Fragmentation statistics (FRAGSTATS) is a computer software program designed to compute a wide variety of landscape metrics for categorical map patterns. FRAGSTATS 4.2 is the most authoritative software to calculate landscape metrics. It can help users to quantify the structure of landscapes. The landscape subject to analysis is user-defined and can represent any spatial phenomenon [35]. Based on the features of the study area, we emphasized on the quantity, shape features, aggregation, and diversity to analyze the spatial pattern of the green landscape [36]. This paper conducted patch level, class level, and landscape-level research on spatial scale, which is ranging from microscope to macroscope. Through landscape pattern metrics calculation and analysis, the changes in landscape pattern from 1995 to 2005 and from 2005 to 2015 were studied, respectively.

According to different ecological significance, the indices were classified into area-edge, shape, core area, aggregation, and diversity. Eleven indices were selected to analyze, including number of patches (NP), patch density (PD), mean patch size (MPS), fractal dimension index (FRAC), Euclidean nearest neighbor (ENN), largest patch index (LPI), Shannon's evenness index (SHEI), Shannon's diversity index (SHDI), aggregation index (AI), contagion index (CONTAG), and interspersion juxtaposition index (IJI). 


\section{Results}

\subsection{Land Use Dynamics}

The land use/cover image results are shown in Figures 5-7. The area and percentage of each land use classification are listed in Table 6. The results showed that land use structure had changed significantly from 1995 to 2015. The major manifestations were the continuous decrease of farmland (from $45.16 \%$ in 1995 to $25.10 \%$ in 2015) and the notable increase of urban land (from $16.33 \%$ in 1995 to $36.05 \%$ in 2015). It could be divided into two stages: namely 1995-2005 and 2005-2015. In the first stage (1995-2005), urban land increased by $289.64 \mathrm{~km}^{2}$, farmland decreased by $559.59 \mathrm{~km}^{2}$, and other land types, including water, bare land, forestland, and grassland, increased slightly; in the second stage (2005-2015), urban land increased by $346.76 \mathrm{~km}^{2}$, while other land types were relatively stable and slightly reduced.

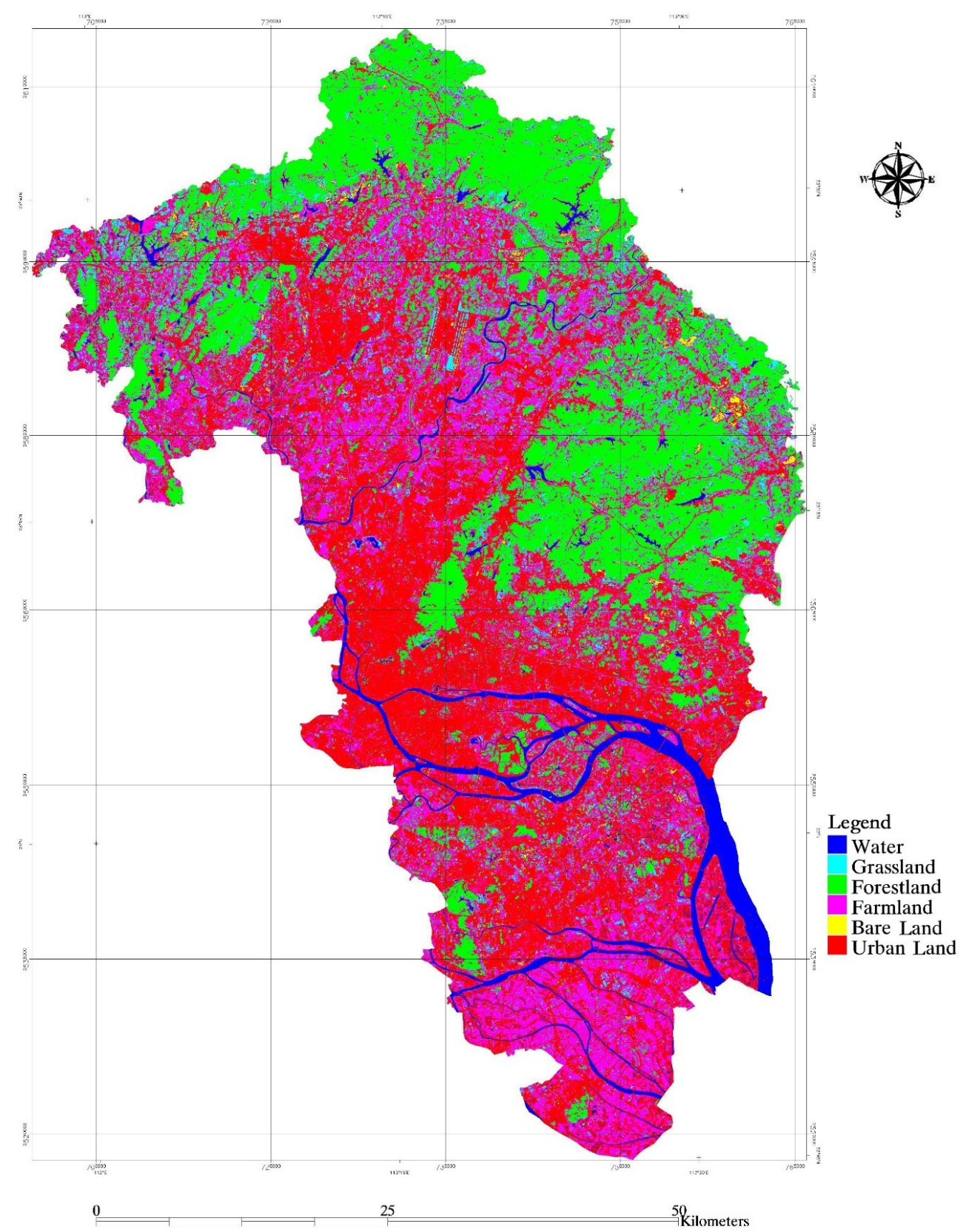

Figure 5. Land use/cover map of the central area of Guangzhou in 2015. 


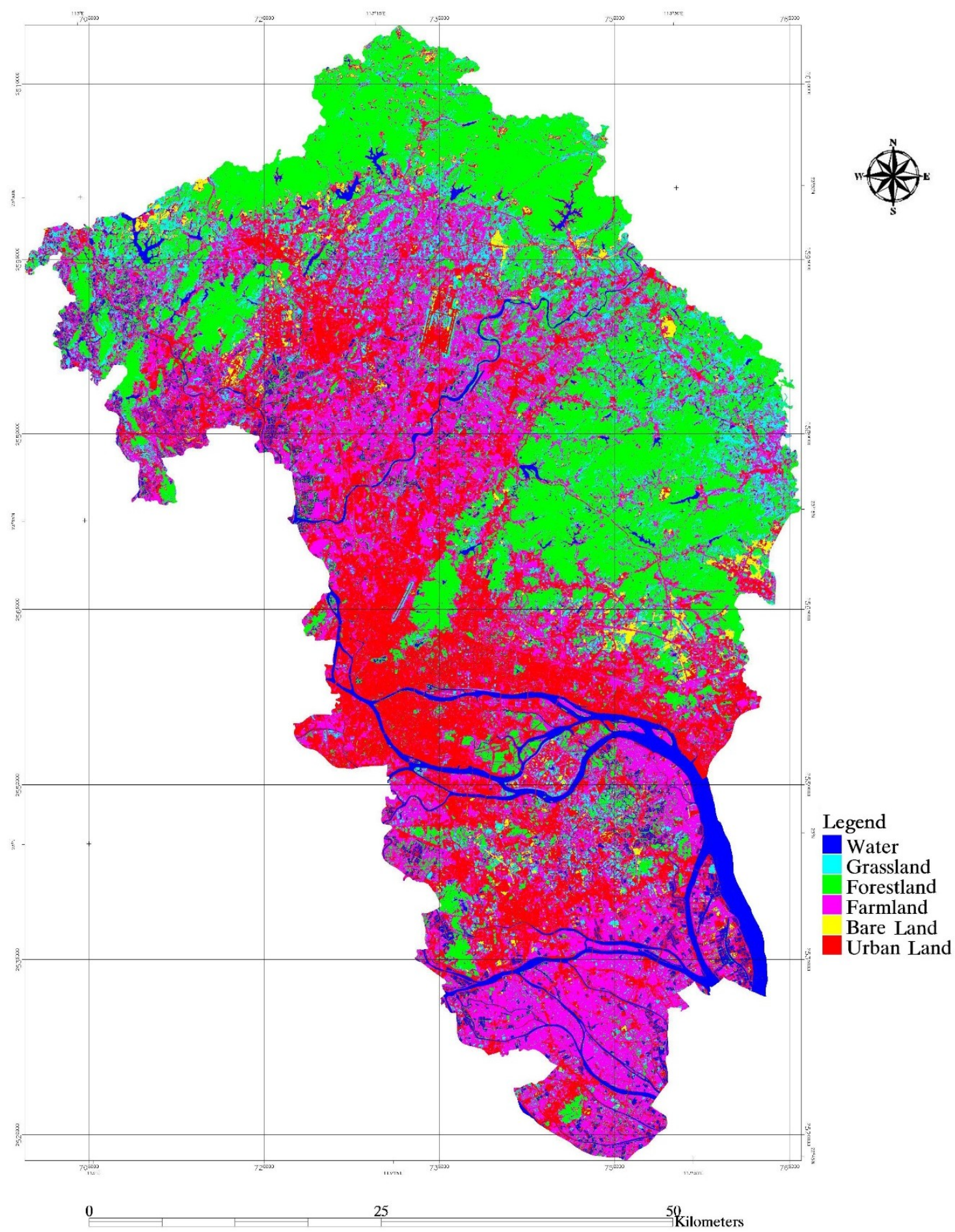

Figure 6. Land use/cover map of the central area of Guangzhou in 2005. 


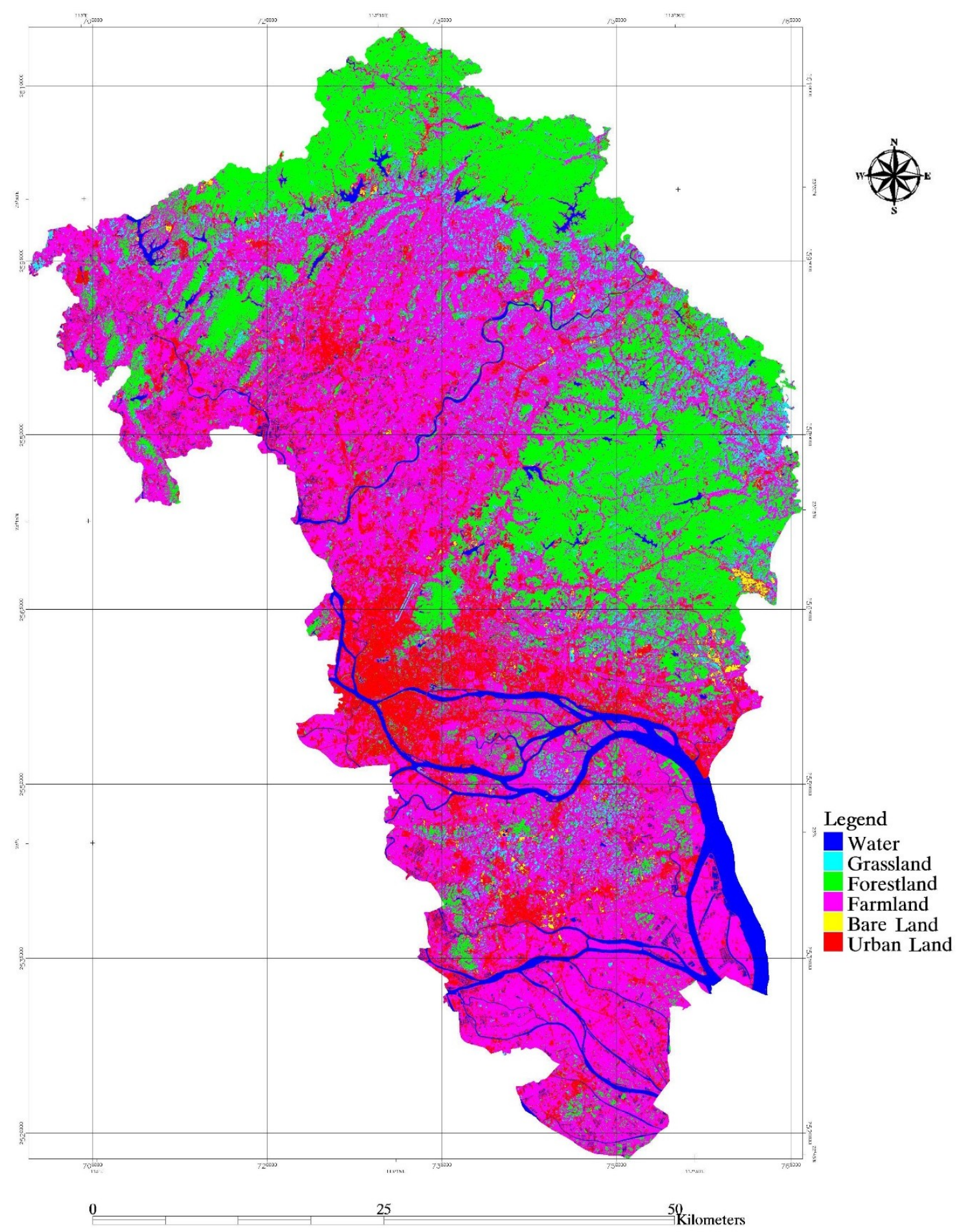

Figure 7. Land use/cover map of the central area of Guangzhou in 1995. 
Table 6. Land-use change statistics.

\begin{tabular}{ccccccc}
\hline Area $\mathbf{( k m}^{2}$ ) Year & Water & Urban Land & Bare Land & Forestland & Farmland & Grassland \\
\hline \multirow{2}{*}{$\mathbf{1 9 9 5}$} & 192.47 & 526.96 & 23.28 & 857.95 & 1457.29 & 169.36 \\
& $5.96 \%$ & $16.33 \%$ & $0.72 \%$ & $26.58 \%$ & $45.16 \%$ & $5.25 \%$ \\
\hline \multirow{2}{*}{2005} & 239.13 & 816.60 & 60.22 & 915.98 & 897.70 & 297.67 \\
& $7.41 \%$ & $25.30 \%$ & $1.87 \%$ & $28.38 \%$ & $27.82 \%$ & $9.22 \%$ \\
\hline \multirow{2}{*}{$\mathbf{2 0 1 5}$} & 160.60 & 1163.36 & 39.55 & 865.47 & 809.99 & 188.23 \\
& $4.98 \%$ & $36.05 \%$ & $1.23 \%$ & $26.82 \%$ & $25.10 \%$ & $5.83 \%$ \\
\hline
\end{tabular}

\subsection{Landscape Pattern Analysis}

\subsubsection{General Landscape Pattern Metrics Analysis}

In order to illustrate the overall trend of landscape pattern change from 1995 to 2015, six indicators were selected for analysis, as shown in Table 7. NP and MPS reflected the spatial landscape pattern, which was used to describe the heterogeneity of the entire landscape. While the value of NP had a good positive correlation with landscape fragmentation, MPS and the landscape fragmentation had a negative correlation. From 1995 to 2005, the value of NP rocketed from 3400 to 4962, while MPS rapidly decreased from 73.69 to 43.64 , reflecting the further fragmentation of the landscape. To some extent, it reflected that human disturbance to landscape had increased significantly in this period. From 2005 to 2015, the value of NP remained stable, and MPS slightly decreased. SHEI and SHDI are significant indices of landscape diversity. They are inversely proportional to landscape dominance. The larger values of SHEI $(0 \leq \mathrm{SHEI} \leq 1)$ and SHDI (SHDI $\geq 0)$ were, the lower the landscape dominance was. As a result, various patches became distributed evenly; the higher the diversity was and the richer the land use was. According to Figure 8, it can be seen that SHEI went up from 0.71 in 1995 to 0.75 in 2005, then slightly went down to 0.72 in 2015; SHDI rapidly went up from 1.37 in 1995 to 1.47 in 2005 , then slightly went down to 1.42 in 2015. It indirectly reflected the state of land-use types from a rapid increase to a slow decrease. The change in this period was closely related to the development of the economy and the adjustment of industrial structure. IJI and CONTAG are widely used for ecological risk assessment, reflecting the condition of landscape contagion and interspersion. IJI and CONTAG describe the degree of agglomeration and extension trend of different patches. When IJI becomes higher, it represents more patch types that are adjacent. While when CONTAG becomes lower, it represents a more intensive landscape pattern with multiple landscape elements. According to Figure 9, the landscape richness increased from 1995 to 2015. To be specific, it rapidly increased from 1995 to 2005 and relatively slightly decreased from 2005 to 2015. The results of these indicators showed strong consistency.

Table 7. Related metrics of overall characteristics of the landscape.

\begin{tabular}{ccccccc}
\hline Year & NP & MPS & SHDI & SHEI & IJI & CONTAG \\
\hline 1995 & 3400 & 73.69 & 1.37 & 0.71 & 60.09 & 54.29 \\
2005 & 4962 & 43.64 & 1.47 & 0.75 & 69.15 & 51.09 \\
2015 & 4942 & 39.37 & 1.41 & 0.72 & 61.68 & 53.38 \\
\hline
\end{tabular}

${ }^{1} \mathrm{NP}=$ Number of Patches; MPS = Mean Patch Size; SHDI = Shannon's Diversity Index; SHEI = Shannon's Evenness Index; IJI = Interspersion Juxtaposition Index; CONTAG = Contagion Index. 


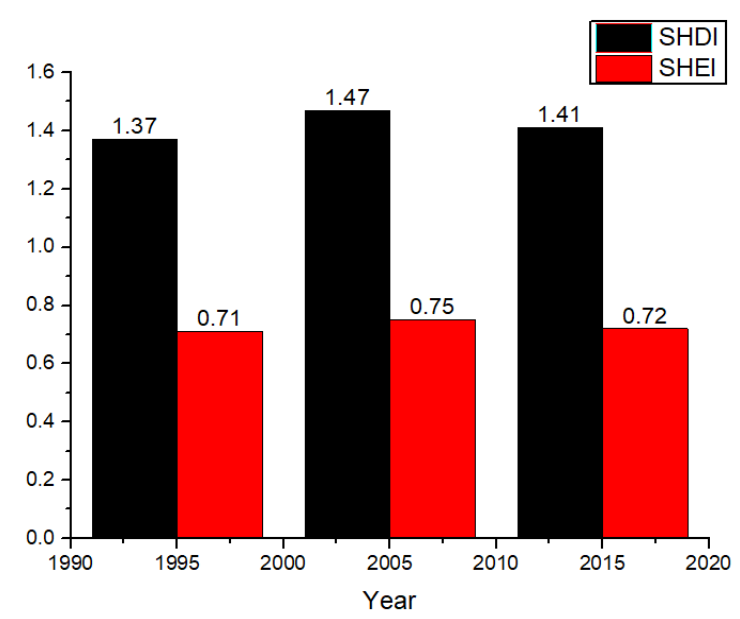

Figure 8. Column chart of Shannon's diversity index (SHDI) and Shannon's evenness index (SHEI).

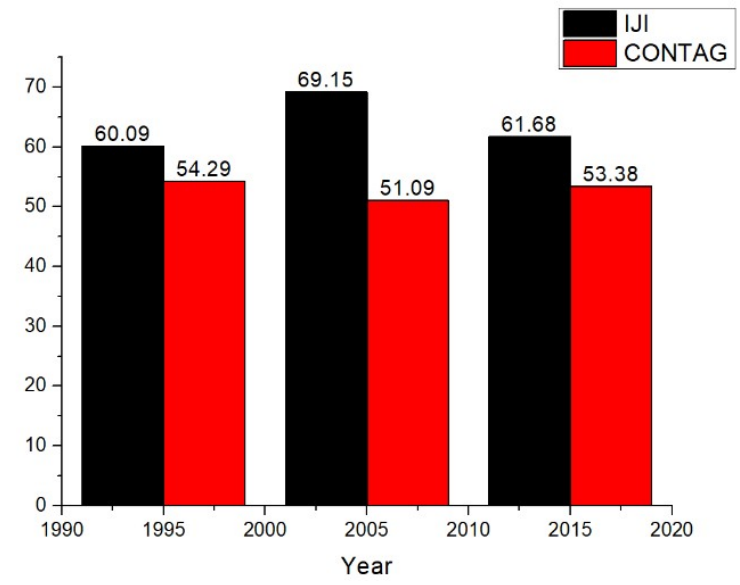

Figure 9. Column chart of interspersion juxtaposition index (IJI) and contagion index (CONTAG).

\subsubsection{Landscape Pattern Metrics Analysis of Different Land Use Types}

The changes in the landscape pattern are the results of changes in various land-use types [37,38]. The individual analysis of landscape pattern metrics of each land-use type can help us better understand the process of urban development. Seven representative indices were selected from three different scale levels: patch, class, and landscape (Table 8).

From the level of patch metrics, ENN reflects the distance between the nearest patches. It is the simplest measure to quantify patch context, which has been used extensively to assess the condition of patch isolation. From 1995 to 2005, the distance among various types of patch significantly decreased, suggesting that the patches became more compact. From 2005 to 2015, the distance of forestland and farmland between patches reduced, while the distance between patches of bare land and grassland slightly increased. Forestland, farmland, and grassland's ENN values were relatively small, indicating that their distribution was more concentrated. The bare land's ENN value was much larger, and its distribution was more scattered.

From the level of class metrics, FRAC is a measurement index of landscape shape. It is mainly used to analyze the complexity of patches. The value of FRAC is between 1 and 2 . When FRAC is closer to 1 , the shape of the patch becomes simpler, implying rectangular patches and obvious artificial influence [39]. From 1995 to 2005, the FRAC value of bare land and grassland increased, and the patch's shape became more complex and irregular. From 2005 to 2015, FRAC values of farmland, bare land and grassland decreased, which means that the shape of the patch tended to be simple and regular and looked like a square. Among them, FRAC values of forestland and farmland were relatively larger than the value of bare land and grassland, implying the shape of patches were relatively complex, 
suggesting human activities had fewer impacts on these type of landscape. However, bare land and grassland's FRAC values were smaller, and the patches' shapes were relatively simple, indicating that these two types were greatly affected by human activities.

From the level of landscape metrics, NP, PD, MPS, and AI, respectively, represents the total number, density, size, and overall aggregation. They form a whole to measure landscape aggregation and fragmentation. According to the results, the changes in the landscape pattern of forestland was the most stable from 1995 to 2015. NP decreased by 47 (4.20\%), and MPS increased by 4.49 (5.87\%). AI slightly decreased from 65.80 in 1995 to 65.59 in 2015. It showed a relatively stable condition in terms of aggregation. Landscape fragmentation of farmland had been increasing sharply with a rapid increase in NP and a sharp decline in MPS. Especially from 1995 to 2005, NP increased by 713 (89.91\%), while MPS decreased by 124.18 (67.56\%). Meanwhile, the AI of farmland significantly decreased by $16.85(27.60 \%)$. Differently, AI of Bare land and grassland had experienced an increase from 1995 to 2005 and a great decrease from 2005 to 2015. In other words, the aggregation of bare land and grassland increased first and then decreased. The NP of grassland increased by $28.96 \%$. The MPS became smaller in 2015 compared with 1995, and the shape of its patch was very close to rectangle, which indicated that the man-made urban green space had increased during this period. It can be found that the LPI of forestland was relatively large, and the change was the most stable. It showed that the forestland maintained its natural growth condition, and there was almost no human interference. From the quantitative point of view, the change of farmland was continuous and the most drastic, sharply decreased from 45.68 to 10.94 , showing that the change of farmland during this period was directly affected by human activities.

Table 8. Landscape pattern metrics of each land-use type.

\begin{tabular}{ccccccccc}
\hline Land Type & Year & NP & PD & MPS & AI & LPI & FRAC & ENN \\
\hline \multirow{3}{*}{ Forestland } & 1995 & 1118 & 1.31 & 76.50 & 65.80 & 38.38 & 1.219 & 705.2 \\
& 2005 & 1160 & 1.28 & 78.36 & 65.20 & 34.08 & 1.212 & 676.6 \\
& 2015 & 1071 & 1.23 & 80.99 & 65.59 & 36.46 & 1.215 & 555.3 \\
\hline \multirow{3}{*}{ Farmland } & 1995 & 793 & 0.54 & 183.82 & 61.04 & 45.68 & 1.285 & 607.2 \\
& 2005 & 1506 & 1.57 & 59.64 & 44.19 & 24.19 & 1.209 & 600.8 \\
& 2015 & 1836 & 2.28 & 43.89 & 37.92 & 10.94 & 1.164 & 546.9 \\
\hline \multirow{3}{*}{ Bare land } & 1995 & 232 & 9.95 & 10.05 & 14.88 & 8.79 & 1.026 & 1522.9 \\
& 2005 & 451 & 7.79 & 12.84 & 21.42 & 3.14 & 1.039 & 1144.8 \\
& 2015 & 414 & 10.98 & 9.11 & 8.57 & 3.35 & 1.018 & 1240.2 \\
\hline \multirow{5}{*}{ Grassland } & 1995 & 1257 & 7.42 & 13.47 & 16.22 & 1.55 & 1.047 & 769.5 \\
& 2005 & 1847 & 6.14 & 16.28 & 20.16 & 1.93 & 1.064 & 681.1 \\
& 2015 & 1621 & 8.76 & 11.42 & 12.49 & 0.80 & 1.033 & 685.6
\end{tabular}

${ }^{1} \mathrm{NP}=$ Number of Patches; PD = Patch Density; MPS = Mean Patch Size; AI = Aggregation Index; LPI = Largest Patch Index; FRAC = Fractal Dimension Index; ENN = Euclidean Nearest Neighbor.

\section{Discussion}

From the beginning of the 1990s, as a regional center, Guangzhou entered the fast urban construction period. With the promulgation of the 15th Round Master Plan in 1996, the northern group of the city was developed. Consequently, Guangzhou had developed from a single-center city to a multi-center city. The multi-center development mode stimulated the development of the suburbs, and the township industrial enterprises developed rapidly. At the same time, many service-oriented villages were formed. From 1995 to 2005, the value of NP greatly increased, and the value of MPS greatly decreased. The fragmentation of the landscape increased significantly as a result. Particularly, the increase of NP and the decrease of MPS of farmland in quantity was the largest among various land-use types. During the first decade, the urbanization in Guangzhou was a spontaneous process in which the rural land was transformed into urban land. The main manifestation was that the rural population was transformed into an urban population in rural areas [40]. The representation in 
land-use change was the non-agricultural conversion of rural land and the expansion of urban land. Non-agricultural conversion of rural land generally refers to the process in which agricultural land was transformed into urban construction land. The driving force of this process was the development of the rural non-agricultural industry. Under the influence of rapid urbanization and industrialization in Guangzhou, the development of rural land conversion was an inevitable trend. As indicated in Figure 10, the proportion of the agricultural industry in Guangzhou had been dropping, accounting for only $1.64 \%$ of the total GDP in 2005. Great changes had taken place in the industrial structure. This process had been promoting the differentiation and reorganization of the productive factors in the rural areas through the expansion of urban land, the evolution of industrial structure, the migration of population, and the construction of infrastructure, and so on, which had profoundly changed the traditional spatial structure of rural land in Guangzhou.

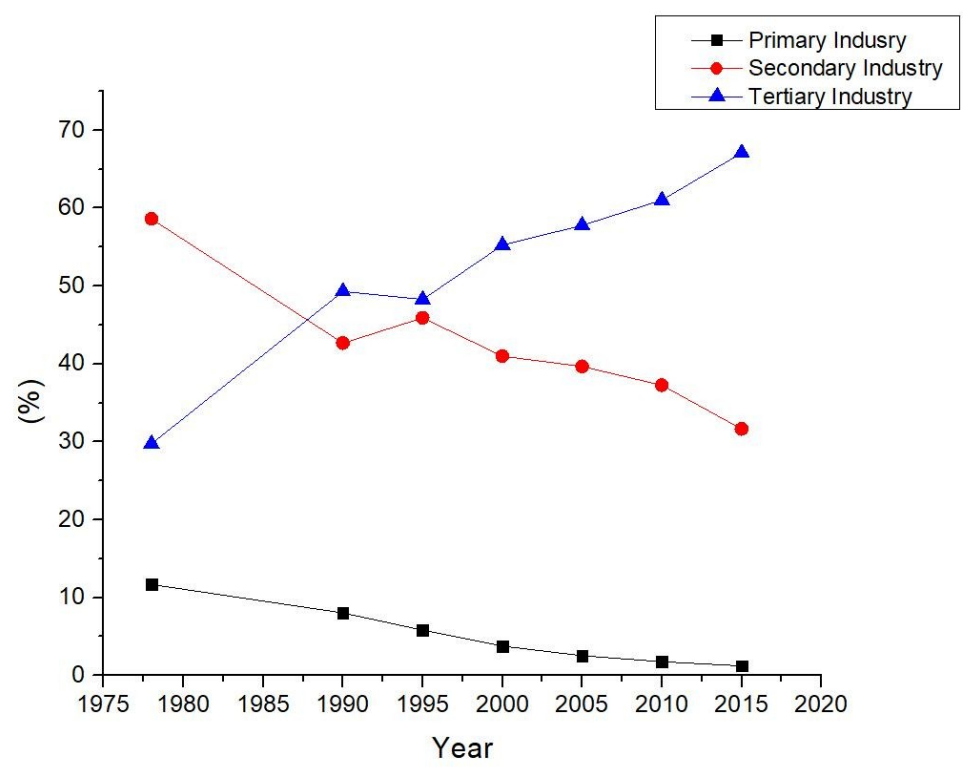

Figure 10. Composition of gross domestic product (GDP) of Guangzhou in main years. Source: Guangzhou Statistical Yearbook.

In general, different metrics of landscape showed the same trend of change. In 2005, the landscape diversity reached the top. Particularly, the value of FRAC of farmland obviously decreased by 0.076 from 1995 to 2005. It showed that human activities directly affected the change in farmland. Therefore, the farmland became more fragmented and scattered. This change was closely related to the extensive and spontaneous construction in Guangzhou. The dominant factors of rural land conversion were complex and diversified. The dominant factors showed a trend of transition from natural and location factors to production and industrial factors, and eventually to life and personal factors. As a result, the spatial manifestation of this transformation was the increase in patch fragmentation. Obviously, it was a development mode that lacked professional planning and guidance. The rapid increase in landscape fragmentation was not conducive to urban sustainability. The city was developed in a low-efficiency approach, and the land resources were wasted.

The 11th Five-Year Plan, promulgated in 2006, emphasizes the optimization of land-use layout and the adjustment of land-use structure, so as to control urban development scale and to realize high-efficiency urban land-use. From 2005 to 2015, urban land was still growing rapidly, while other land-use types slightly decreased (Figure 11). Additionally, the government promulgated a series of policies to protect farmland, which had reduced the loss of farmland to some extent. However, it was still an obvious contradiction between the supply and demand of urban land. From 2005 to 2015, urban land had been greatly supplemented through the redevelopment of low-efficiency land. During this period, the improvement of urban infrastructure was one of the reasons for the decline in 
MPS. For example, the increase in urban road density made the landscape patches smaller. However, the fragmentation of landscape decreased. This contrast mainly resulted from three aspects: (1) urban development area and ecological conservation area were clearly defined in Guangzhou. Specifically, the natural land, including forestland, grassland, and farmland, was zoned; (2) many small towns had developed into urban centers, and the scattered urban land gathered into these centers. As a result, the agglomeration of urban land obviously increased. The multi-center structure of Guangzhou became more apparent; (3) the establishment of greenway improved the connection of fragmented patches. Generally, greenway refers to ecological corridors of different sizes. It includes regional greenway, urban greenway, and community greenway in Guangzhou.

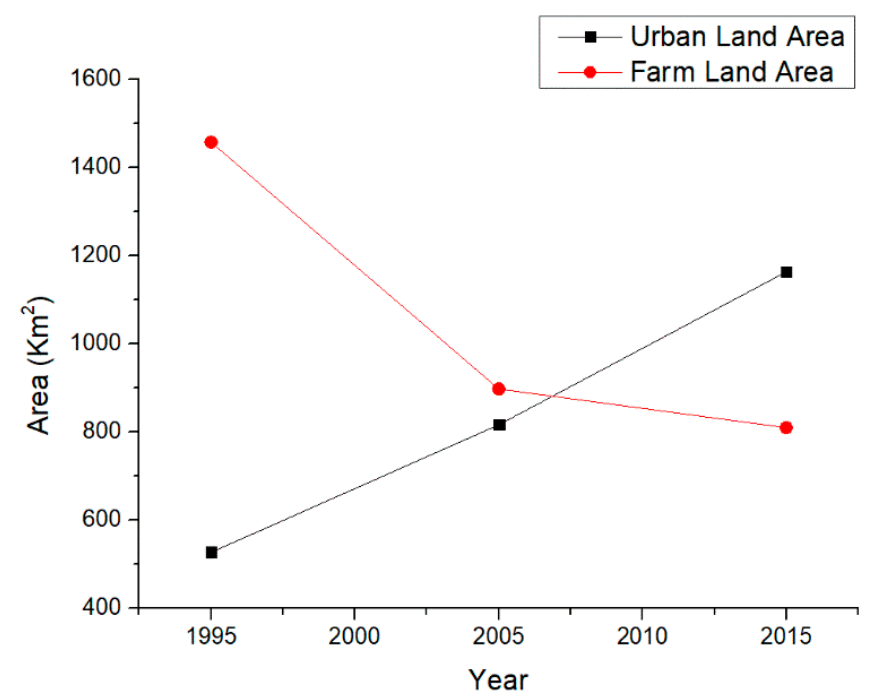

Figure 11. The changes in urban land and farmland in 1995, 2005, 2015.

The outline of the Pearl River Delta (PRD) Reform and Development Plan, promulgated in 2008, stressed the importance of improving the quality of the urban environment. In 2010, Urban Green System Planning of Guangzhou (2001-2020) was officially promulgated, and the development objective of Guangzhou was pushed forward: improving the structure of urban ecological space system, forest conservation, and the establishment of the greenway. We should optimize the construction of green space in central urban areas and strengthen the construction of street green space and community parks. Besides, it was required by the plan to reach $41.5 \%$ green coverage rate in the administrative region of Guangzhou and $40 \%$ in the central area by 2015 .

From 1995 to 2015, the proportion of grassland and forestland increased slightly. Particularly, the landscape pattern aggregation of forestland increased as well, indicating that the forestland system has a better continuity while maintaining a stable natural growth state. The main forms of urban green space are forestland and grassland. Although the growth of forestland and grassland was only $7.52 \mathrm{~km}^{2}$ and $18.87 \mathrm{~km}^{2}$, compared with remote sensing images, the increase of green space in urban core areas (Haizhu, Tianhe, Yuexiu) was obvious (Figure 12). On the basis of protecting the existing green space, a large number of integrated parks had been planned through park reconstruction and expansion (Figure 13). Additionally, small-scale green spaces were encouraged to be established by a variety of forms, such as community parks, village parks, and roadside green space. Community parks exist in residential communities of different scales and provide ecosystem services for residents. Village parks are built in rural villages or suburbs. It provides space for villagers' public activities and still retains rural landscape patches, such as farmland and natural waters. Roadside green space is built outside urban roads. It is relatively small and scattered in the city. The fragmentation of grassland increased at the beginning and then decreased, which was also directly related to these government policies. Urban ecological environment quality had been greatly improved during this period. 


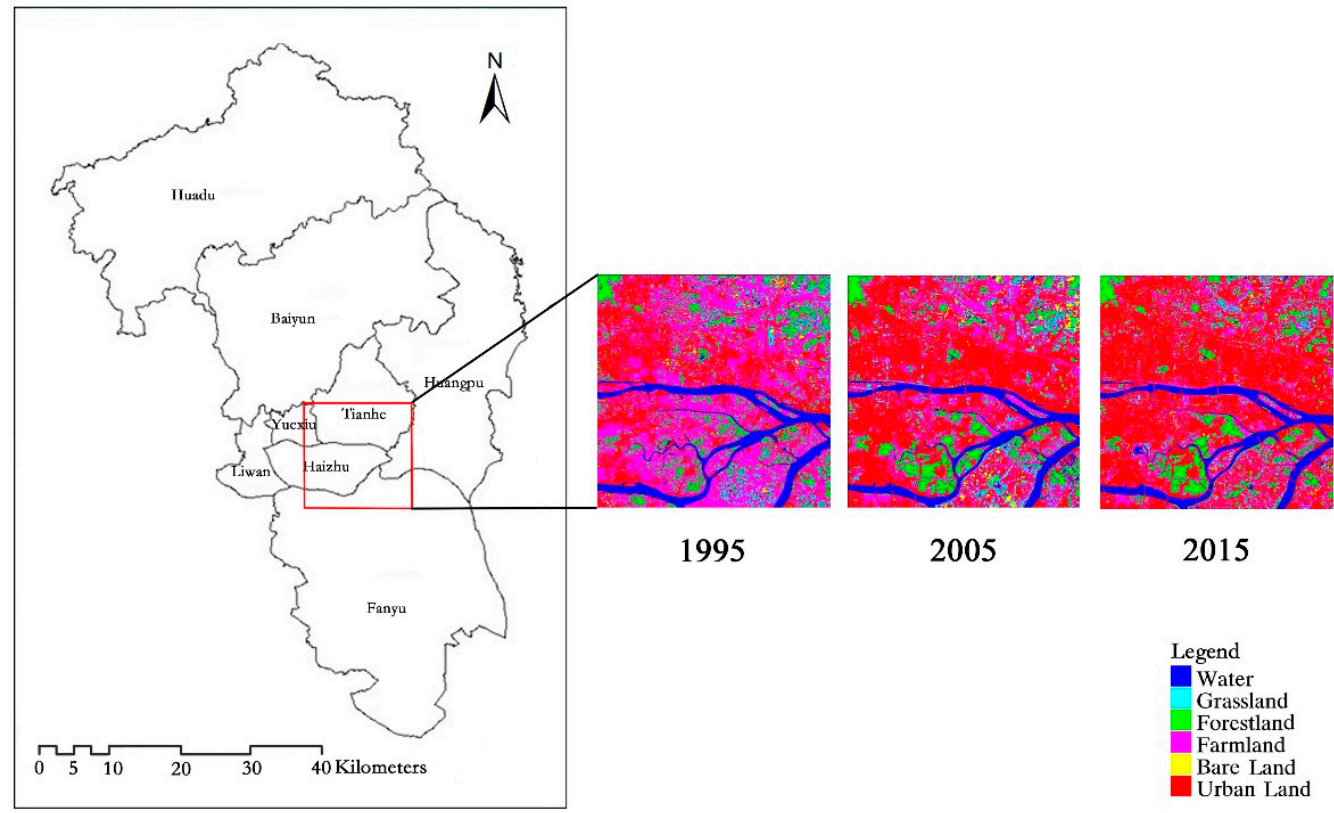

Figure 12. The changes in green space in core areas of Guangzhou in 1995, 2005, 2015.

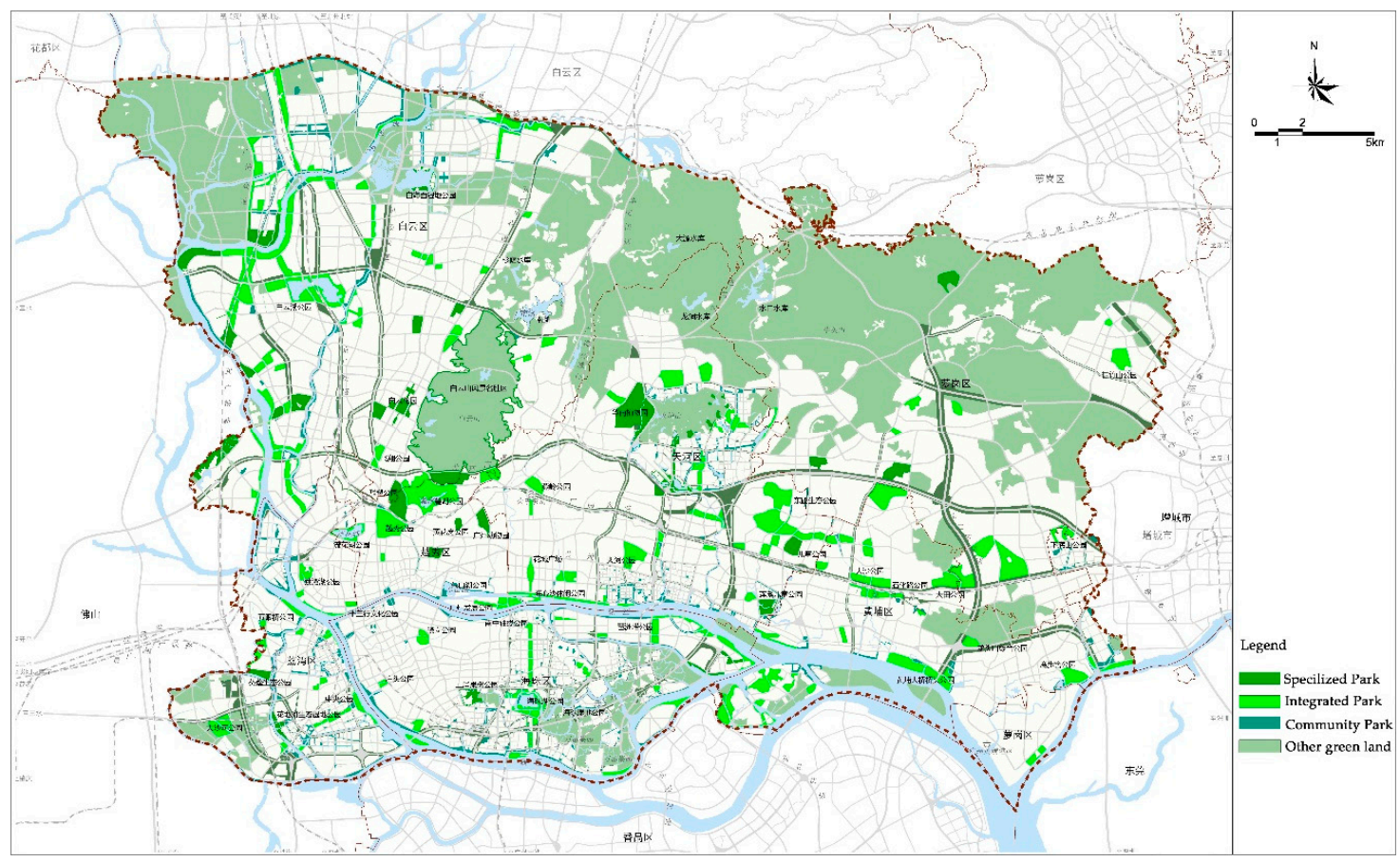

Figure 13. Green system planning of the central area of Guangzhou. Source: Planning Bureau of Guangzhou.

The improvement of the ecological environment benefits from the guidance of planning and policies. Among them, the most important thing is the delineation of basic ecological control lines, including basic farmland protection areas, rural parks, and ecological corridors. This strategy reasonably controls the size of the city and optimizes the urban structure. According to Urban Green System Planning of Guangzhou (2001-2020), a three-level park system, including a specialized park, integrated park, and community park, had been established, which forms a network-based green space system [41]. Additionally, the greenway system had been well established on different scales. Based on actual completion and statistics, the number of parks in Guangzhou reached 246 in 2015, and the green coverage rate in developed areas reached $41.53 \%$, achieving the goal of $41.5 \%$ (Figures 14 and 15). 


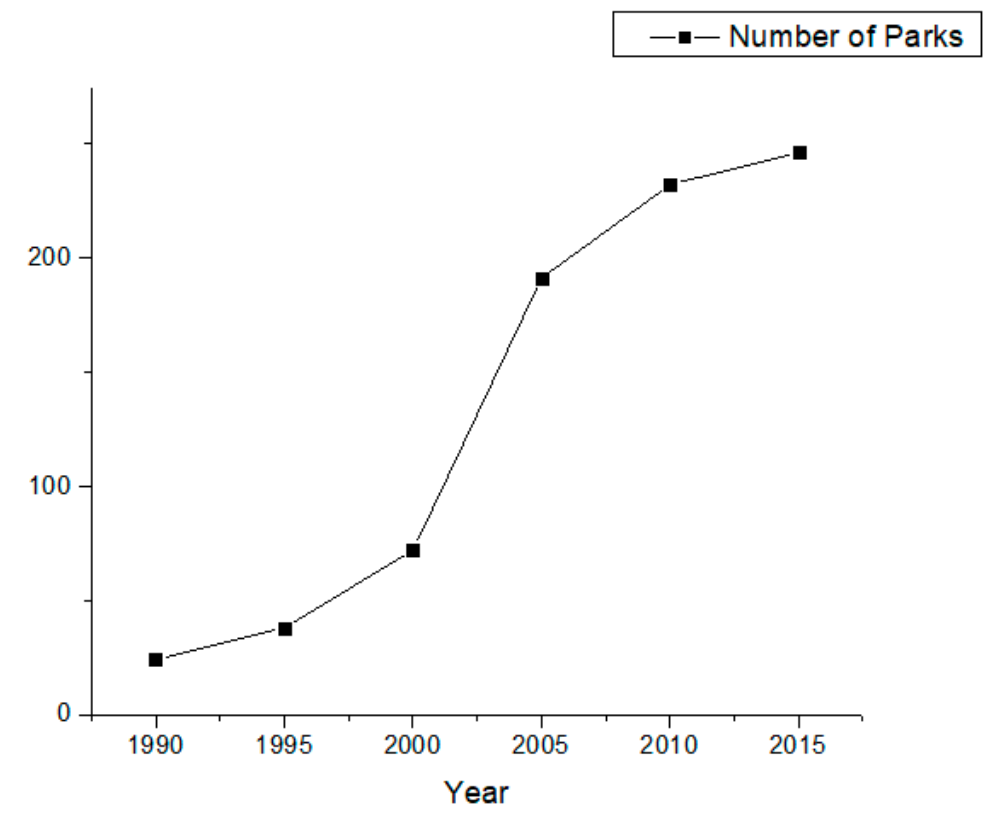

Figure 14. The number of parks in Guangzhou in main years.

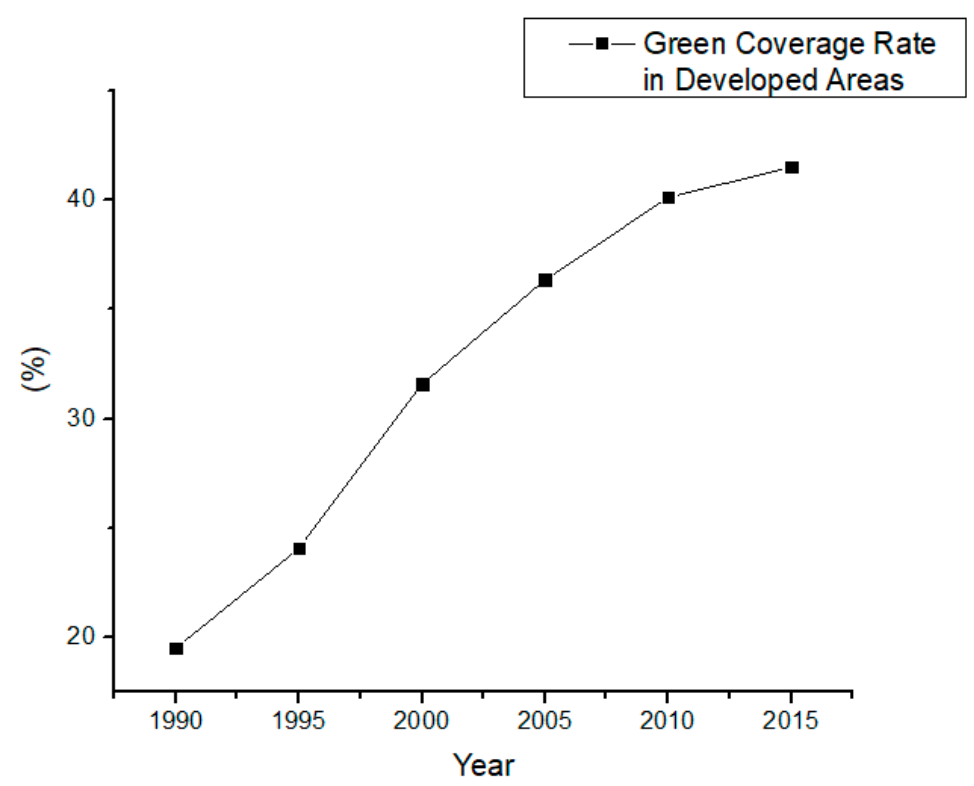

Figure 15. The green coverage rate in developed areas of Guangzhou in main years.

\section{Conclusions}

Based on the land-use data of 1995, 2005, and 2015, the spatial-temporal dynamics of land-use and landscape pattern in Guangzhou were analyzed through RS and GIS technologies. In the context of rapid urbanization, the driving force, which led to the change, was explored. According to the results, the change in land-use and landscape pattern in the second decade was quite different from that in the first one. The mode of urban land-use was transformed from incremental development to inventory development, which also meant an extensive mode to an efficient one. The focus of urban development had become the improvement of living quality.

(1) From 1995 to 2015, the urban land of Guangzhou greatly increased from $526.96 \mathrm{~km}^{2}(16.33 \%)$ to $1163.36 \mathrm{~km}^{2}$ (36.05\%). From 1995 to 2005, the increase of urban land was mainly from the non-agricultural conversion of rural land. The driving force of this process was the development of the 
rural non-agricultural industry. From 2005 to 2015, the increase in urban land mainly resulted from the redevelopment of low-efficiency lands, such as bare land.

(2) Farmland greatly decreased from $45.16 \%$ in 1995 to $27.82 \%$ in 2005 . A large number of farmland was transformed into urban land. After 2005, a series of policies were promulgated to protect farmland. The loss of farmland had been obviously controlled. As a result, farmland only decreased by $2.72 \%$ until 2015.

(3) Landscape fragmentation is mainly affected by human activity. From 1995 to 2005, human activity in terms of urban construction was extensive and spontaneous. The landscape fragmentation increased greatly. From 2005 to 2015, the efficient land-use that focuses on compact and the establishment of the urban green system had reduced the landscape fragmentation. This was helpful to improve urban sustainability.

Although the importance of agriculture in Guangzhou has been decreasing, it still has great social and environmental significance according to the policy. With the end of the rapid non-agricultural conversion of rural land, farmland will remain in a relatively stable state. On the other hand, the basic ecological control lines will be strictly enforced. As a result, the spatial pattern, including ecological, agricultural, and urban space, will remain stable and continue to be optimized. In order to improve the urban environment, urban green space will become more systematic from a macro perspective; from the micro point of view, with the increase of community parks, roadside green space, and village parks, as well as roof greening, the fragmentation of urban green space will be higher. Eventually, the city and green space will become integrated, and urban environmental quality of Guangzhou will be further improved.

Author Contributions: Conceptualization S.L. and Q.Y.; methodology, S.L. and Q.Y.; software, S.L. and Q.Y.; validation, S.L. and C.W.; formal analysis, S.L. and Q.Y.; investigation, S.L. and C.W.; resources, S.L. and Q.Y.; data curation, Q.Y.; writing—original draft preparation, S.L.; writing—review and editing, S.L. and Q.Y.; visualization, S.L. and C.W.; supervision, Q.Y.; project administration, S.L.

Funding: This research received no external funding.

Conflicts of Interest: The authors declare no conflict of interest.

\section{References}

1. Ren, Z.B.; Fu, Y.; Du, Y.X.; Zhao, H.B. Spatiotemporal patterns of urban thermal environment and comfort across 180 cities in summer under China's rapid urbanization. Peer] 2019, 7, 7424. [CrossRef] [PubMed]

2. Jin, K. Spatio-Temporal Variations of Vegetation Cover and its Relationships between Climate Change and Human Activities over CHINA. Ph.D. Thesis, Northwest A\&F University, Yangling, China, April 2019.

3. Zong, J.F.; Lin, Z.J. 70 years of retrospect and reflection on China's urbanization. Econom. Probl. 2019, 07, 1-8.

4. Kremer, P.; Haase, A.; Hasse, D. The future of urban sustainability: Smart, efficient, green or just? Introduction to the special issue. Sustain. Cities Soc. 2019, 51, 101761. [CrossRef]

5. Chan, K.M.; Vu, T.T. A landscape ecological perspective of the impacts of urbanization on urban green spaces in the Klang Valley. Appl. Geogr. 2017, 85, 89-100. [CrossRef]

6. Costanza, R.; d'Arge, R.; de Groot, R. The value of the world's ecosystem services and natural and natural capital. Nature 1997, 3, 253-260. [CrossRef]

7. Stessens, P.; Khan, A.Z.; Huysmans, M.; Canters, F. Analysing urban green space accessibility and quality: A GIS-based model as spatial decision support for urban ecosystem services in Brussels. Ecosyst. Serv. 2017, 28, 328-340. [CrossRef]

8. Lu, Y.; Gan, H.H.; Shi, Z.J.; Liu, Z.L. Soil Fertility Quality Assessment and Managing Measures for Urban Green Space in Shenzhen City. J. Soil. Water Conserv. 2015, 19, 153-155.

9. Ali, B.; Frederic, C.; Bernard, K. Improving the multi-functionality of urban green spaces: Relations between components of green space and urban services. Sustain. Cities Soc. 2018, 43, 1-10. [CrossRef]

10. Hashem, D.; Parviz, A.; Mahdis, M. Land use change, urbanization, and change in landscape pattern in a metropolitan area. Sci. Total Environ. 2019, 655, 707-719. [CrossRef]

11. Turner, M.G. Landscape ecology: The effect of pattern on process. Annu. Rev. Ecol. Syst. 1989, 20, 171-177. [CrossRef] 
12. Wu, Z.; Chen, R.S.; Michael, E.W.; Dhritiraj, S.; Di, X. Changing urban green space in Shanghai: Trends, drivers and policy implications. Land Use Policy 2019, 87, 104080. [CrossRef]

13. Gillanders, S.N.; Coops, N.C.; Wulder, M.A. Multitemporal remote sensing of landscape dynamics and pattern change: Describing natural and anthropogenic trends. Prog. Phys. Geogr. 2008, 32, 503-528. [CrossRef]

14. Yang, X.; Zheng, X.-Q.; Chen, R. A land use change model: Integrating landscape pattern indexes and Markov-CA. Ecol. Model. 2014, 283, 1-7. [CrossRef]

15. Zhou, X.L.; Wang, Y.C. Spatial-temporal dynamics of urban green space in response to rapid urbanization and greening policies. Landsc. Urban Plan. 2011, 100, 268-277. [CrossRef]

16. Chen, B.M.; Liu, X.W.; Yang, H. Review of most recent progresses of study on land use and land cover change. Prog. Geogr. 2003, 22, 22-29.

17. Yu, H.P.; Cheng, P.G.; Xia, Y.Q. Application of 3S Technology in Land Dynamic Monitoring. J. Anhui Agric. Sci. 2011, 3, 1844-1846.

18. Wang, C.D.; Wang, Y.T.; Wang, R.Q.; Zheng, P.M. Modeling and evaluating land-use/land-cover change for urban planning and sustainability: A case study of Dongying city, China. J. Clean. Prod. 2018, 172, 1529-1534. [CrossRef]

19. Yu, W.H.; Zang, S.Y.; Wu, C.S. Analyzing and modeling land use land cover change (LUCC) in the Daqing City, China. Appl. Geogr. 2011, 31, 600-608. [CrossRef]

20. Gong, J.Z.; Xia, B.C. Spatio-temporal characteristics of vegetation fraction calculation from TM imagines in Guangzhou from 1990 to 2005. Ecol. Environ. 2016, 15, 1289-1294.

21. Chen, Y.H. Application of GIS and remote sensing technology in the production of image map. Electron. Test 2016, 11, 107-108.

22. Dai, C.D.; Hu, D.Y. Information characteristics of TM data. Remote Sens. Environ. 1987, 2, 7-10.

23. Dai, C.D.; Lei, L.P. TM Image spectral information characteristics and optimum band combination. Remote Sens. Environ. 1984, 4, 282-2.

24. Bruzzone, L. Detection of changes in remotely-sensed images by the selective use of multi -spectral information. Int. J. Remote Sens. 1997, 18, 3883-3888. [CrossRef]

25. Zhao, Y.S. The Principle and Method of Analysis of Remote Sensing Application, 2nd ed.; Science Press: Beijing, China, 2003.

26. Measuring Vegetation (NDVI and EVI). Available online: http://earthobservatory.nasa.gov/Features/ MeasuringVegetation/measuring_vegetation_2.php (accessed on 19 July 2019).

27. Alejandro, C.S.; Jorge, L.B. Delineation of suitable areas for crops using a multi-criteria evaluation approach and land use/cover mapping: A case study in Central Mexico. Agric. Syst. 2003, 77, 117-136.

28. Byrne, G.F.; Crapper, P.F.; Mayo, K.K. Monitoring land-cover by principal component analysis of multi-temporal Landsat data. Remote Sens. Environ. 1980, 10, 175-184. [CrossRef]

29. Feng, D.J.; Li, Y.S.; Lan, Y. The automatic detection methods of changing information for dynamic monitoring by principal component transform. Comput. Eng. Appl. 2004, 36, 202-205.

30. Mo, D.L.; Liu, K.J.; Cao, B.C.; Bao, Y.Q. Remote sensing image change detection based on principal component analysis. Image Technol. 2013, 25, 53-56.

31. Cihlar, J.; Xiao, Q.H.; Chen, J. Classification by progressive generalization: A new automated methodology for remote sensing multichannel data. Int. J. Remote. Sens. 1998, 19, 2685-2704. [CrossRef]

32. Li, D.; Luo, Y.F.; Meng, Y.B.; Wang, X.; Li, M.L. Study on spatial change of land use based on GIS. Mod. Surv. Mapp. 2019, 42, 13-17.

33. Fisher, P.F. Visualization of the reliability in classified remote sensing images. PE RS 1994, 60, 905-910.

34. Yi, L.; Zhang, G. Object-oriented remote sensing imagery classification accuracy assessment based on confusion matrix. Proc. Int. Conf. Geoinf. 2012, 1-8. [CrossRef]

35. Lamine, S.; Petropoulos, G.P.; Sudhir, K.S. Quantifying land use/land cover spatio-temporal landscape pattern dynamics from Hyperion using SVMs classifier FRAGSTATS. Geo. Int. 2018, 33, 862-878. [CrossRef]

36. UMass Landscape Ecology Lab. FRAGSTATS: Spatial Pattern Analysis Program for Categorical Maps. Available online: http://www.umass.edu/landeco/research/fragstats/fragstats.html (accessed on 19 July 2019).

37. Li, X.; Lu, L.; Cheng, J.D.; Xiao, H.L. Quantifying landscape structure of the Heihe river basin, north-west China using FRAGSTATS. J. Arid Environ. 2001, 48, 521-535. [CrossRef] 
38. Chen, W.B.; Xiao, D.N.; Li, X.Z. Classification, application and construction of landscape metrics. Chin. J. Appl. Ecol. 2002, 1, 121-125.

39. Meghann, M.; Paul, B.; Anna, J.; Ebru, E.; Rave, M. Green space spatial characteristics and human health in an urban environment: An epidemiological study using landscape metrics in Sheffield, UK. Ecol. Indic. 2019, 106, 105464. [CrossRef]

40. Liu, Y.; Zhou, C.S.; Huang, W.L.; Zhu, Q.Q. Spatial features and forming mechanism of rural land non-agricultural degree in metropolitan areas: A case study of Guangzhou City. Prog. Geogr. 2018, 37, 1119-1130.

41. Liao, Y.T.; Xiao, R.B. Establishing urban green space planning system. Planner 2012, 3, 46-49.

(C) 2019 by the authors. Licensee MDPI, Basel, Switzerland. This article is an open access article distributed under the terms and conditions of the Creative Commons Attribution (CC BY) license (http://creativecommons.org/licenses/by/4.0/). 